\title{
Determinants of Self-referral among Outpatients at Referral Hospitals in East Wollega, Western Ethiopia
}

\author{
Edosa Tesfaye Geta ${ }^{1, *}$, Yibeltal Siraneh ${ }^{2}$, Elias Ali Yesuf ${ }^{2}$ \\ ${ }^{1}$ School of Public Health, Institute of Health Science, Wollega University, Nekemte, Ethiopia \\ ${ }^{2}$ Department of Health Policy and Management, Faculty of Public Health, Institute of Health, Jimma University, Jimma, Ethiopia
}

Email address:

edotesfa@yahoo.com (E. T. Geta)

${ }^{*}$ Corresponding author

\section{To cite this article:}

Edosa Tesfaye Geta, Yibeltal Siraneh, Elias Ali Yesuf. Determinants of Self-referral among Outpatients at Referral Hospitals in East Wollega, Western Ethiopia. Journal of Family Medicine and Health Care. Vol. 7, No. 3, 2021, pp. 57-64. doi: 10.11648/j.jfmhc.20210703.11

Received: July 28, 2021; Accepted: August 9, 2021; Published: August 23, 2021

\begin{abstract}
Patient self-referral is a process through which patients refer themselves to higher level health facilities without seeing anyone else first or being advised to refer themselves by a health professional. Despite the expansion in the number of health facilities, this phenomenon is perceived when patients routinely access referral hospitals. This study aimed to determine the magnitude and identify the determinants of outpatient self-referral at referral hospitals. It was conducted in East Wollega zone of Oromia National Regional State, Ethiopia. A cross-sectional study design was used to collect data between December 1 and 30, 2017. For the study, a 404 samples size was determined using a single population proportion formula. Data entry and analysis were done using SPSS version 20. Descriptive statistics, binary and multiple logistic regressions were performed. A total of 404 outpatients were included, thereby making the response rate of $96.8 \%$. Amongst the 391 outpatients who were interviewed, $330(84.4 \%)$ engaged in self-referral. The factors significantly associated with outpatient self-referral were referral information (Adjusted odds ratio and $95 \%$ confidence interval $(\mathrm{CI})=0.32[0.15-0.70]$ ), illness severity (Adjusted odds ratio and $95 \% \mathrm{CI}=3.50[1.47-8.30]$ ), confidence of patients in getting care providers (Adjusted odds ratio and $95 \mathrm{CI}=3.03$ [1.51-6.07]), availability of laboratory services (Adjusted odds ratio and 95\% CI $=5.00[2.20-11.23]$ ) and drugs (Adjusted odds ratio and $95 \% \mathrm{CI}=2.37$ [1.01-5.53]) and quality of health services (Adjusted odds ratio and 95\% CI $=3.00$ [1.42-6.33]). The proportion of outpatient self-referral was high and it was associated with referral information, patient confidence in getting healthcare providers, the severity of illness, availability of laboratory services, drugs and the quality of services. A monitoring system of the referral linkage of health facilities should be established at all levels and health facilities should create awareness in the community regarding the referral linkages of health facilities.
\end{abstract}

Keywords: Self-referral, Outpatient Visit, Referral Hospital, Health Care Utilization

\section{Introduction}

Patient self-referral is a condition when patients refer themselves to higher level health facilities without having to see anyone else first or without being told to refer themselves by another health professional [1]. Primary health care facilities need to maintain a close relationship between all the levels of a health system and the referral linkage of health facilities is very important in providing health care for the people of any country [2].

In many developing countries, a high proportion of clients or patients seen at the outpatient departments at secondary health care facilities could be appropriately looked after at primary health care centers [3].

Ethiopia has successfully implemented its strategy of expanding and rehabilitating primary health care facilities to make health services closer to the community and easily accessible and to ensure further decentralization efforts have been done. However, health care utilization at the nearest primary health care facilities in the country is still low [4].

Referral functions are usually invoked to justify the privileged resource allocations of higher health facilities. To counter-argue with hard evidence of reduced referral caseloads may strengthen the bargaining position of lowerlevel facilities and the expansion of overcrowded referral 
health facilities in fact attending an excessive proportion of common conditions without offering significant comparative benefits to these patients can be discouraged [5].

According to the study conducted in South Africa, more than $50 \%$ of patients seen at referral health facilities outpatient departments could have been managed at the primary level health facilities. Most acute cases at the hospital were selfreferral where the patients probably did not seek health care until they became severely ill or sought care at other levels of health care, and then came to the referral hospital [6].

In spite of primary health care elements providing essential care and prevention resources for rural populations in Ethiopia, patients often access secondary levels of care without first using primary health care provided by primary level health facilities [7]. The study conducted in western Ethiopia at the general hospital revealed $82 \%$ of patients bypassed the first level referral facilities and $74.9 \%$ of them did not first contact the nearest health facilities [8] and the fundamental message of referral system is still unchanged [9]. Referral flows should be understood because of their efficiency and effectiveness implications. Little is known about outpatient self-referral in Ethiopia. So determining the magnitude, identifying the reasons why outpatients self-refer and factors that contribute to self-referral to referral health facilities are very important in the provision of health care in the country.

\section{Methods and Participants}

\subsection{Study Design and Participants}

This study was conducted from December 01 to 30, 2017 using a cross-sectional study design in East Wollega zone of Oromia National Regional State, Ethiopia. The zone had two referral public hospitals (Nekemte referral hospital and Wollega University referral hospital) which are found in Nekemte town, located 333 Kilometer from Addis Ababa, three primary public hospitals, 60 public health centers, 298 health posts, 1 regional laboratory, 1 blood bank, 1 nongovernmental health center, 217 private clinics, 45 drug stores and 22 drug vendors.

All patients visited the outpatient departments of the study health facility willing to participate in this study were included in the study after taking consent and patients whose age was less than 15 years their caregivers were interviewed. Patients with serious physical, mental problems, and emergency cases were excluded from the final interview of the study. Patients whose age was less than 15 years and without caregivers were excluded.

\subsection{Sampling and Data Collection Procedures}

The required sample size for the study was determined by using the formula of a single population proportion [10] with the assumption of $50 \%$ outpatient self-referral rate, $95 \%$ confidence interval with $5 \%$ margin of error and $5 \%$ nonresponse rate.

$$
\mathrm{n}=(\mathrm{Z} \alpha / 2)^{2} * \mathrm{P}(1-\mathrm{P}) / \mathrm{d}^{2}=(1.96)^{2} \mathrm{x} 0.5(1-0.5) /(0.05)^{2}=404(1)
$$

Data were collected from outpatients visited the Nekemte referral hospital. Nekemte referral hospital was selected purposely because the other referral hospital in East Wollega was less than one year since it was established and became functional during the study period.

By using a systematic sampling method, 404 respondents were selected. The interval of the respondents for the interview was determined by dividing the daily average total number of outpatients flow by the number of participants planned to be interviewed daily.

Therefore, every $\mathrm{K}^{\text {th }}$ from Nekemte referral hospital (180/24=7th) study participant was selected from registration books at the triage room. A simple random sampling technique was employed to select the first study participant.

The structured questionnaire was developed in English after reviewing relevant literature and the questionnaire was translated into local language Afan Oromo which was used for the final interview. Three data collectors and one supervisor were assigned and trained for data collection. All supervisor and data collectors were those had BSc degrees and experience in data collection. Data were collected by face-to-face interviews using a structured questionnaire. Patients who completed their outpatient services and returned to leave the study hospital and willing to participate in this study were interviewed (exit interview).

\subsection{Study Variables}

The dependent variable was outpatient self-referral and independent variables were individual factors (sociodemographic characteristics, severity of illness, information about referral linkage, self-reported chief complaints) and institutional factors (location of health care facilities, access to public transportation, proximity to home of health care facilities, proximity to workplace of health care facility, affordability of health services, health care provider type, type of proximal health facility, length of waiting time in health facility, reputation of health facility, availability of adequate drugs, availability of laboratory services, availability of radiological services, quality of services, health care provider courtesy and respect).

\subsection{Data Management and Analysis}

The completed questionnaires were being checked for completeness, consistency and coded by the principal investigator and supervisor. Questionnaires for participants were translated into the local language (Afan Oromo) and retranslated back into English to ensure its consistency. The questionnaires were pre-tested using $40(10 \%)$ of sample size at the Wollega University referral hospital and to ensure that whether it is clear or not for respondents.

After completeness of each questionnaire checked, data entry and analysis were made using SPSS for windows version 20 software [11]. Descriptive statistics were performed for all study variables. Binary logistic regression was performed to identify the association between each independent and dependent variable. All variables associated with outpatient 
self-referral bypassing primary health facilities in binary logistic regression analysis were considered as candidate variables with $\mathrm{p} \leq 0.25$ and those candidate variables were entered into multiple logistic regression model. The statistical significance of predictors of outpatient self- referral in the final model was declared at $\mathrm{p}<0.05$.

\subsection{Ethical Statement}

Official letter for ethical clearance was obtained from the Institutional Review Board of Jimma University, Institute of Health. Formal letter of permission was taken from the East Wollega Zonal health department and given to the study health facility to obtain consent and required information from all subjects and also confidentiality was maintained.

\section{Results}

\subsection{Socio-demographic Characteristics}

A total of 404 of outpatients were included in the study making $391(96.8 \%)$ of the response rate. Among 391 outpatients visited Nekemte referral hospital outpatient departments $330(84.4 \%)$ were self-referred outpatients who had bypassed the nearest health facilities. The mean age of self-referred outpatients was $27.5 \pm 17.4$ years. Among selfreferred outpatients, more than half of patients $177(53.6 \%)$ were females and the majority of the self-referred outpatients $212(64.2 \%)$ were from urban, and $212(64.3 \%)$ were literate (Table 1).

Table 1. Socio-demographic characteristics and self-referral of outpatients visited outpatient departments at Nekemte referral hospital in East Wollega, Ethiopia 2017.

\begin{tabular}{|c|c|c|c|c|}
\hline \multirow{2}{*}{\multicolumn{2}{|c|}{ Socio-demographic Characteristics }} & \multicolumn{3}{|l|}{ Self-referral } \\
\hline & & Yes $N=330(\%)$ & No $N=61(\%)$ & Total $\mathrm{N}=391(\%)$ \\
\hline \multirow{2}{*}{ Sex } & Male & $153(46.4)$ & $19(31.1)$ & $172(44)$ \\
\hline & Female & $177(53.6)$ & $42(73.9)$ & $219(56)$ \\
\hline \multirow{5}{*}{ Age (years) } & $\leq 10$ & $57(17.3)$ & $3(4.9)$ & $60(15.3)$ \\
\hline & $11-20$ & $68(20.6)$ & $10(16.4)$ & $78(20)$ \\
\hline & $21-30$ & $96(29.1)$ & $24(39.3)$ & $120(30.7)$ \\
\hline & $31-40$ & $44(13.3)$ & $6(9.8)$ & $50(12.8)$ \\
\hline & $\geq 51$ & $36(10.9)$ & $5(8.2)$ & $41(10.5)$ \\
\hline \multirow{2}{*}{ Marital Status } & Single & $146(44.2)$ & $16(41.0)$ & $162(41.4)$ \\
\hline & Married & $184(55.8)$ & $45(59.0)$ & $229(58.6)$ \\
\hline \multirow{3}{*}{ Place of Residence } & Urban & $212(64.2)$ & $26(42.6)$ & $238(60.9)$ \\
\hline & Rural & $118(35.8)$ & $35(57.4)$ & $153(39.1)$ \\
\hline & Illiterate & $106(32.1)$ & $29(47.5)$ & $135(34.5)$ \\
\hline \multirow{5}{*}{ Educational Status } & Read \&Write & $12(3.6)$ & $3(4.9)$ & $15(3.8)$ \\
\hline & $2^{\text {nd }}$ cycle (grade $\left.5-8\right)$ & $51(15.5)$ & $9(14.8)$ & $60(15.3)$ \\
\hline & Secondary \&Prep (9-12) & $50(15.2)$ & $6(9.8)$ & $56(14.3)$ \\
\hline & Diploma & $40(12.1)$ & $10(16.4)$ & $50(12.8)$ \\
\hline & Degree and above & $26(7.9)$ & $3(4.9)$ & $29(7.5)$ \\
\hline \multirow{2}{*}{ Employment Status } & Employed & $69(20.9)$ & $19(31.1)$ & $88(22.5)$ \\
\hline & Unemployed & $261(79.1)$ & $42(68.9)$ & $303(77.5)$ \\
\hline
\end{tabular}

\subsection{Reasons for Outpatients Self-referral to Referral Hospitals}

From a total of 330 self-referred outpatients interviewed at Nekemte referral hospital, 301 (91.2\%) of patients responded as the study hospital was not the health facility closest to their residence place and among 301, 160 (53.2\%) did not visit the nearest health facilities for their current health problems.

The type of proximal health facilities bypassed: 46 (15.5\%) were public hospitals, $145(48.8 \%)$ were public health centers and $110(35.7 \%)$ were private clinics. Among the respondents, $190(48.6 \%)$ visited Nekemte referral hospital for their first time and the majority of self-referred outpatients $239(72.4 \%)$ had no referral information about health facilities referral linkage. The perceived severity of illness of self-referred outpatients: 124 (37.6\%) were severe and 206 (62.4\%) were mild whereas the majority of the category of perceived selfreported chief complaints 250 (75.8\%) were acute.
The interviewed outpatients reasoned out different reasons from their previous experience of nearest health facility visits why they preferred to visit outpatient departments of referral hospital bypassing the proximal health facilities that they visited in previous. From a total of 330 self-referred outpatients for 169 (51.2\%) participants the proximal health facility location was not convenient to them and $259(78.5 \%)$ of the proximal health facilities had no transportation access to be visited and $239(72.4 \%)$ participants were not confident in getting health care providers type they want to see for their health problems at the proximal health facilities.

From their previous visits of proximal health facilities, 153 (46.4\%) of participants said the health care providers courtesy and respect at the facility were not good and $289(87.6 \%)$ preferred medical doctors to other clinicians to see firstly for their any health problems. More than half of the participants 222 $(67.3 \%)$ preferred to visit referral hospitals to get more and detail explanations about their health problems that they did not 
get during the proximal health facility visits. The other reasons for self-referral of outpatients to referral hospitals were the expectation of availability of adequate drugs and laboratory services at referral hospitals. From self-referred outpatients, 194
(58.8\%) and $216(65.5 \%)$ participants did not get adequate drugs and laboratory services respectively as they want at proximal health facilities during their previous visits (Table 2).

Table 2. Reasons for Outpatient Self-referral to Nekemte referral hospital in East Wollega, Oromia National Regional State, Ethiopia, 2017.

\begin{tabular}{|c|c|c|c|}
\hline \multirow{2}{*}{ Reasons for Self-referral } & & \multicolumn{2}{|l|}{ Responses } \\
\hline & & Yes $(\%)$ & No $(\%)$ \\
\hline \multirow[t]{2}{*}{ Is NRH the proximal facility to your residence place? } & & $29(8.8)$ & $301(91.2)$ \\
\hline & Hospital & $46(15.3)$ & $255(84.7)$ \\
\hline \multirow[t]{2}{*}{ If NRH is not proximal, what was the type of proximal health facility? } & Health center & $145(48.2)$ & $156(51.8)$ \\
\hline & Private clinic & $110(36.5)$ & $191(63.5)$ \\
\hline Referral Information & & $91(27.6)$ & $239(72.4)$ \\
\hline If NRH is not proximal, did you visit nearest HF for your current problem? & & $124(41.2)$ & $177(58.8)$ \\
\hline \multirow[t]{2}{*}{ If $\mathrm{NRH}$ is not proximal, did you visit the proximal HF in last 12 months } & & $292(97)$ & $9(3)$ \\
\hline & First time & $154(46.7)$ & $176(53.3)$ \\
\hline \multirow[t]{2}{*}{ How often you visit NRH? } & Occasionally & $79(23.9)$ & $251(76.1)$ \\
\hline & Often & $97(29.4)$ & $233(70.1)$ \\
\hline \multirow{2}{*}{ Perceived severity of illness } & Severe & $124(37.6)$ & $206(62.4)$ \\
\hline & Mild & $206(62.4)$ & $124(37.6)$ \\
\hline \multirow{2}{*}{ Self-reported chief complaints } & Chronic & $80(24.2)$ & $250(75.8)$ \\
\hline & Acute & $250(75.8)$ & $80(24.2)$ \\
\hline Access to public transportation to visit the proximal HF & & $71(21.5)$ & $259(78.5)$ \\
\hline Location of the proximal HF was convenient for you to visit? & & $161(48.8)$ & $169(51.2)$ \\
\hline Were health services affordable at the proximal HF? & & $275(83.3)$ & $55(16.7)$ \\
\hline Were you confident in getting all type of providers at proximal HF? & & $91(27.6)$ & $239(72.4)$ \\
\hline \multirow{2}{*}{$\begin{array}{l}\text { Patients' preference of health care provider to see firstly for their any health } \\
\text { problem }\end{array}$} & Doctors & $289(87.6)$ & $41(12.4)$ \\
\hline & $\mathrm{BSc} / \mathrm{Ho}$ & $41(12.4)$ & $289(87.6)$ \\
\hline Did you get explanation about your health problems at proximal HF? & & $108(32.7)$ & $222(67.3)$ \\
\hline Was provider courtesy and respect good at proximal HF? & & $153(46.4)$ & $177(53.6)$ \\
\hline Was time to get health service short at the proximal HF? & & $255(77.3)$ & $75(22.7)$ \\
\hline Was the reputation of the proximal HF good? & & $128(38.8)$ & $202(61.2)$ \\
\hline Did you get adequate drugs in the HF during your visit? & & $136(41.2)$ & $194(58.8)$ \\
\hline Did you get laboratory services at proximal HF? & & $114(34.5)$ & $216(65.5)$ \\
\hline Availability of radiology services in the proximal HF? & & $35(10.6)$ & $295(89.4)$ \\
\hline \multirow{2}{*}{ Rate the quality of health services at the proximal HF } & Good & 113 (34.2) & $217(65.8)$ \\
\hline & Poor & $217(65.8)$ & $113(34.2)$ \\
\hline
\end{tabular}

Notes: $\mathrm{NRH}=$ Nekemte Referral Hospital, $\mathrm{HF}=$ Health Facility, $\mathrm{HO}=$ Health Officer

\subsection{Predictors of Outpatient Self-referrals to Referral Hospitals}

From multiple logistic regression analysis (Table 3), the referral information on the linkage of health facilities was very strongly associated with outpatient self-referral to visit outpatient departments of referral hospitals (Adjusted odds ratio and $95 \% \mathrm{CI}=0.32[0.15-0.70])$. That means outpatients who had information about referral linkage of health facilities were $68 \%$ less likely to self-refer to referral hospitals than those patients who had no information about the referral linkage of health facilities.

Regarding the perceived severity of illness, it was strongly associated with outpatient self-referral to referral hospitals (Adjusted odds ratio and 95\% $\mathrm{CI}=3.50$ [1.47-8.30]). This odds ratio depicts that those patients perceived their illness as severe were 3.5 times more likely to self-refer to referral hospitals than those patients perceived their illness as mild.

The study result showed that the confidence of patients in getting health care provider types they want at proximal health facilities was also strongly associated with outpatient self-referral to referral hospitals (Adjusted odds ratio and
$95 \% \mathrm{CI}=3.60[1.55-8.32])$. This indicates that patients who were not confident in getting health care providers they want at the proximal health facilities were 3.6 times more likely to self-refer to referral hospitals than those patients who were confident in getting health care providers they want at proximal health facilities.

According to the study, the patients' expectations about the availability of advanced laboratory services and drugs at health facilities were significantly associated with outpatient self-referral to referral hospitals (Adjusted odds ratio and 95\% $\mathrm{CI}=5.00$ [2.20-11.23]) and 2.37 (1.01-5.53) respectively. This shows that those patients did not expect to get laboratory services and drugs at the proximal health facilities and had an expectation of the availability of advanced laboratory and drugs at referral hospitals were five and 2.4 times more likely to self-refer to referral hospitals respectively than those patients that obtained laboratory services and drugs at proximal health facilities.

The perceived quality of health services was very strongly associated with outpatient self-referral to referral hospitals (Adjusted odds ratio and 95\% $\mathrm{CI}=3.00$ [1.42-6.33]) and this indicates that odds of self-referral of patients perceived quality of health services at proximal health facility was poor 
were three times more likely to self-refer to referral hospitals than those patients perceived the quality of health services at proximal health facility was good.

For those patients, the location of proximal health facility was convenient and had access to transportation to visit the health facilities were also strongly associated with outpatient self-referral to the referral hospitals (Adjusted odds ratio and $95 \% \mathrm{CI}=3.75$ [1.56-9.02]) and 3.88 (1.65-9.11) respectively.
This implies that the patients for whom the proximal health facility location was inconvenient were 3.8 more likely to self-refer than those patients for whom the location of proximal health facility was convenient. Similarly, those patients that had no access to transportation to visit proximal health facility were almost four times more likely to selfrefer than those had access to transportation to visit the nearest health facilities.

Table 3. Predictors of Outpatient self-referral to Nekemte referral hospital in East Wollega, Oromia National Regional State, Ethiopia, 2017.

\begin{tabular}{|c|c|c|c|c|}
\hline \multirow{2}{*}{ Variables } & \multicolumn{2}{|l|}{ Self-referral } & \multicolumn{2}{|c|}{ Odds Ratio and $95 \%$ CI } \\
\hline & Yes $(\%)$ & No $(\%)$ & Crude odds ratio & Adjusted odds ratio \\
\hline Sex & 330 & 61 & & \\
\hline Male & $153(46.4)$ & $19(31.1)$ & $1.911(1.066-3.425)$ & $1.807(0.827-3.948)$ \\
\hline Female & $177(53.6)$ & $42(26.2)$ & 1 & 1 \\
\hline Marital Status & 330 & 61 & & \\
\hline Single & $146(44.2)$ & $16(41.0)$ & $2.232(1.212-4.109)$ & $1.252(0.492-3.189)$ \\
\hline Married & $184(55.8)$ & $45(73.8)$ & 1 & 1 \\
\hline Residence place & 330 & 61 & & \\
\hline Urban & $212(64.2)$ & $26(42.6)$ & $2.419(1.388-4.21)$ & $1.978(0.927-4.222)$ \\
\hline Rural & $118(35.8)$ & $35(57.4)$ & 1 & 1 \\
\hline Educational status & 330 & 61 & & \\
\hline Illiterate & $106(32.1)$ & $29(47.5)$ & $0.422(.119-1.492)$ & $0.193(0.028-1.327)$ \\
\hline Read \&Write & $12(3.6)$ & $3(4.9)$ & $0.462(0.081-2.630)$ & $0.391(0.024-6.346)$ \\
\hline $1^{\text {st }}$ cycle $(1-4)$ & $45(13.6)$ & $1(1.6)$ & $5.192(.513-52.524$ & $1.377(0.081-23.260)$ \\
\hline $2^{\text {nd }}$ cycle $(5-8)$ & $51(15.5)$ & $9(14.8)$ & $0.654(0.163-2.623)$ & $0.287(0.037-2.247)$ \\
\hline Grade (9-12) & $50(15.2)$ & $6(9.8)$ & $0.962(.222-4.160)$ & $0.365(0.056-2.946)$ \\
\hline Diploma & $40(12.1)$ & $10(16.4)$ & $0.462(0.116-1.837)$ & $0.463(.063-3.412)$ \\
\hline Degree $\&$ above & $26(7.9)$ & $3(4.9)$ & 1 & 1 \\
\hline Jobs status & 330 & 61 & & \\
\hline Employed & $69(20)$. & $19(31.1)$ & $0.584(0.320-1.068)$ & $0.567(0.250-1.286)$ \\
\hline Unemployed & $261(79.1)$ & $42(68.9)$ & 1 & 1 \\
\hline Proximal HF type & 298 & 61 & & \\
\hline Hospital & $46(15.5)$ & $9(14.8)$ & $0.627(0.250-1.569)$ & $0.731(0.150-3.557)$ \\
\hline Health center & $145(48.8)$ & $39(63.9)$ & $0.456(0.232-0.896)$ & $0.716(.236-2.176)$ \\
\hline Private clinic & $110(35.7)$ & $13(21.3)$ & 1 & 1 \\
\hline Current visiting of nearest HF & 301 & 61 & & \\
\hline Yes & $124(41.2)$ & $43(70.5)$ & $0.293(0.162-0.532)$ & $0.478(0.224-1.019)$ \\
\hline No & $177(58.8)$ & $18(29.5)$ & 1 & 1 \\
\hline Referral linkage information & 330 & 61 & & \\
\hline Yes & $91(27.6)$ & $30(49.2)$ & $0.393(0.225-0.687)$ & $0.324(0.150-0.696) * *$ \\
\hline No & $239(72.4)$ & $31(50.8)$ & 1 & 1 \\
\hline Frequency of NRH visiting & 330 & 61 & & \\
\hline First time & $154(46.7)$ & $36(59)$ & $0.617(.317-1.204)$ & $0.768(0.296-1.992)$ \\
\hline Occasionally & $79(23.9)$ & $11(18)$ & $1.037(0.446-2.410)$ & $1.363(0.433-4.286)$ \\
\hline Often & $97(29.4)$ & $14(23)$ & 1 & 1 \\
\hline Perceived severity of illness & 330 & 61 & & \\
\hline Severe & $124(37.6)$ & $13(21.3)$ & $2.223(1.158-4.266)$ & $3.496(1.473-8.297) * *$ \\
\hline Mild & $206(62.4)$ & $48(78.7)$ & 1 & 1 \\
\hline Self-reported chief complaint & 330 & 61 & & \\
\hline Chronic & $80(24.2)$ & $23(37.7)$ & $0.529(.297-0.940)$ & $0.903(0.335-2.432)$ \\
\hline Acute & $250(75.8)$ & $38(62.3)$ & 1 & 1 \\
\hline Affordability of Services from HF & 330 & 61 & & \\
\hline Yes & $275(83.3)$ & $47(77)$ & $1.489(0.767-2.891)$ & $0.459(0.174-1.211)$ \\
\hline No & $55(16.7)$ & $14(23)$ & & 1 \\
\hline Convenience location of the HF & 330 & 61 & & \\
\hline Yes & $161(48.8)$ & $40(65.6)$ & 1 & 1 \\
\hline No & $169(51.2)$ & $21(34.4)$ & $1.999(1.130-3.538)$ & $3.750(1.560-9.017) * *$ \\
\hline Access to transportation to visit HF & 330 & 61 & & \\
\hline Yes & $71(21.5)$ & $30(49.2)$ & 1 & 1 \\
\hline No & $259(78.5)$ & $31(50.8)$ & $4.138(2.350-7.288)$ & $3.879(1.651-9.114) * *$ \\
\hline Confident to get providers at $\mathrm{HF}$ & 330 & 61 & & \\
\hline Yes & $91(27.6)$ & $36(59 \%)$ & 1 & 1 \\
\hline No & $239(72.4)$ & $25(41)$ & $3.782(2.151-6.651)$ & $3.595(1.554-8.317)^{* *}$ \\
\hline Patients' preference of provider type & 330 & 61 & & \\
\hline $\mathrm{BSc} / \mathrm{Ho}$ & $41(12.4)$ & $3(4.9)$ & $0.365(0.109-1.127)$ & $0.793(0.172-3.646)$ \\
\hline
\end{tabular}




\begin{tabular}{|c|c|c|c|c|}
\hline \multirow{2}{*}{ Variables } & \multicolumn{2}{|l|}{ Self-referral } & \multicolumn{2}{|c|}{ Odds Ratio and $95 \%$ CI } \\
\hline & Yes $(\%)$ & No (\%) & Crude odds ratio & Adjusted odds ratio \\
\hline Doctors & $289(87.6)$ & $58(95.1)$ & 1 & 1 \\
\hline Did you get explanation at the HF? & 330 & 61 & & \\
\hline Yes & $108(32.7)$ & $8(13.1)$ & $0.655(0.375-1.143)$ & $0.926(0.349-2.456)$ \\
\hline No & $222(67.3)$ & $53(86.9)$ & ( & 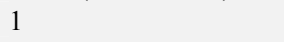 \\
\hline Care provider courtesy and respect & 330 & 61 & & \\
\hline Good & $153(46.4)$ & $37(60.7)$ & $0.561(0.321-0.979)$ & $1.433(0.612-3.359)$ \\
\hline Poor & $177(53.6)$ & $24(39.3)$ & 1 & 1 \\
\hline Time to get service was short at $\mathrm{t} \mathrm{HF}$ & 330 & 61 & & \\
\hline Yes & $255(77.3)$ & $41(67.2)$ & $1.659(0.916-3.002)$ & $0.813(0.294-2.250)$ \\
\hline No & $75(22.7)$ & $20(32.8)$ & 1 & 1 \\
\hline Availability of laboratory services & 330 & 61 & & \\
\hline Yes & $114(34.5)$ & $44(72.1)$ & 1 & 1 \\
\hline No & $216(65.5)$ & $17(27.9)$ & $4.904(2.681-8.971)$ & $4.966(2.199-11.216)^{* * * *}$ \\
\hline Availability of drugs in the facility & 330 & 61 & & \\
\hline Yes & $136(41.2)$ & $50(82)$ & 1 & 1 \\
\hline No & $194(58.8)$ & $11(18)$ & $6.484(3.257-12.90)$ & $2.366(1.013-5.526)^{*}$ \\
\hline Did you get radiology services at $\mathrm{HF}$ & 330 & 61 & & \\
\hline Yes & $35(10.6)$ & $14(23)$ & $0.398(0.199-0.796$ & $0.893(0.291-2.736)$ \\
\hline No & $295(89.4)$ & $47(77)$ & 1 & 1 \\
\hline Rate quality of services from the HF & 330 & 61 & & \\
\hline Good & $113(34.2)$ & $37(60.7)$ & 1 & 1 \\
\hline Poor & $217(65.8)$ & $24(39.3)$ & $2.961(1.688-5.192)$ & $2.996(1.418-6.328) * *$ \\
\hline
\end{tabular}

Notes: $*$ P-value $<0.05, * *$ P-value $<0.01, * * *$ P-value $<0.001$ and $1=$ reference, $\mathrm{CI}=$ Confidence Interval, NRH=Nekemte Referral Hospital, $\mathrm{HF}=$ Health Facility, $\mathrm{HO}=$ Health Officer

\section{Discussion}

According to the study findings, the proportion of outpatient self-referral to referral hospitals bypassing the proximal health facilities was $84.4 \%$. This finding shows the magnitude of patients' self-referral was higher than the magnitude of patients' self-referral in India which was $76.2 \%$ [12], in Tanzania 72.5\% [13], but lower than that of Ghana which was 90\% [14] and in Australia, where self-referral has been possible for over 30 years, approximately $65 \%$ of patients use self-referral [15].

This difference might be due to those studies findings show the proportion of general patients' self-referral whereas this study shows the magnitude of outpatients' self-referral to visit outpatient departments of referral hospitals.

According to the study, the odds ratio depicts that those outpatients perceived their illness as severe were 3.5 more likely to self-refer to referral hospitals than those patients perceived their illness as mild (Adjusted odds ratio of $95 \%$ $\mathrm{CI}=3.50[1.47-8.30])$. But, the patients who had health facilities referral linkages information were $68 \%$ less likely to self-refer to referral hospitals than those patients that had no information about the referral linkage of health facilities (Adjusted odds ratio of $95 \% \mathrm{CI}=0.32 \quad(0.15-0.70)$. The finding was consistent with the study finding conducted in Ethiopia which shows those patients needing specialized care from higher level health facilities were less likely to have sought prior care at lower health facilities and in similar way patients that knew the closest health facility as first referral level were $76 \%$ less likely self-refer and those obtained information on referral systems were $35 \%$ less likely to selfrefer $[7,8]$.

Also, another study in Kenya showed that the severity of illnesses was found to be statistically significant to patients' self-referral [16]. This might be when patients perceived their health problems as severe they may seek special health care from higher level health facilities and bypass the proximal health facilities. Regarding the referral information, when these patients obtained information on the type of health services and health care providers at proximal health facilities and referral health facilities they might be able to utilize health care at the proximal health facilities.

Outpatients who were not confident in getting all type of health care providers at proximal health facilities were 3.6 times more likely to self-refer to referral hospitals than those patients that were confident to in getting all type of health care providers at proximal health facilities (Adjusted odds ratio and $95 \% \mathrm{CI}=3.60[1.55-8.32])$. The study conducted in India showed that the patient-related factors of directly selfreferral to secondary and tertiary referral health facilities were due to the faith of patients on the doctors and health facilities $(81 \%)$ and availability of the specialists at referral health facilities (54.5\%) [12]. Another study conducted in Midwestern also showed that $37.5 \%$ of reasons for selfreferral were preferences of health care providers type that patients preferred to directly access a specialist to save time or to choose their own specialist [17].

This could be explained by the fact that from the finding of the study, $72.1 \%$ of self-referred patients were confident in getting all type of health care providers they want to see for their health problems at referral health facilities than the nearest health facilities and $87.6 \%$ of the self-referred patients preferred to see medical doctors firstly for their any health problems that were not available at primary level health facilities.

According to the study, $65.5 \%$ of the patients did not obtain laboratory services at proximal health facilities during 
their previous visits and preferred visiting referral hospitals to get advanced laboratory services. This shows that the patients who did not obtain laboratory services at the proximal health facilities and expected the availability of laboratory services at referral hospitals were almost five times more likely to self-refer to referral hospitals than those obtained laboratory services at proximal primary health facilities (Adjusted odds ratio of $95 \% \mathrm{CI}=4.50$ [2.20-11.22]). In addition to this, the patients who did not obtain adequate drugs from the proximal health facilities were 2.4 times more likely to self-refer to referral hospitals to obtain adequate drugs when compared to those patients obtained adequate drugs from the proximal facilities (Adjusted odds ratio of 95\% CI=2.37 [1.01-5.53]).

This finding is in line with the finding of the study conducted in Tanzania which shows that reasons for patients self-referral from lower level health facilities were lack of expertise and equipment were the most common factors given for self-referral $(96.3 \%)$ and about half of the lower level health facilities reported lack of drugs $(53.8 \%)$ and due to these factors patients bypassed the proximal health facilities [13].

From the study result, $65.8 \%$ of the self-referred outpatients perceived the quality of health services at proximal health facilities was poor and preferred self-referral to referral hospitals. Consequently, the odds of self-referral of patients perceived the quality of health services at the proximal health facility was poor were three times more likely to self-refer than those patients perceived the quality of health services at proximal health facilities was good (Adjusted odds ratio and 95\% CI=3.00 [1.42-6.33]).

Similarly, the study conducted in Kenya identified that the quality of health services is one of an institutional determinant of patients' self-referral to referral health facilities [18]. In addition to this, according to the study conducted in Chad patients who know the other health care providers do not offer the specific services the quality they need $13.3 \%$ higher probability the patients had bypassed the proximal providers to seek care [19].

The patients who perceived the location of the proximal health facility was inconvenient for them and not accessible to transportation were almost four times more likely to selfrefer compared to those patients perceived the location of the proximal health facility was convenient for them and accessible to transportation (Adjusted odds ratio and 95\% $\mathrm{CI}=3.75$ [1.56-9.02]) and $\mathrm{CI}=3.88$ (1.65-9.11) respectively.

Similarly, the study conducted in Kenya revealed that location of health facilities is one of the institutional determinants cited as the reasons why they prefer to seek health services from referral health facilities bypassing lower level health facilities [18] and study in Honduras revealed that due to geographical accessibility $84 \%$ of patients directly referred to higher referral hospitals by passing health facilities that functioning as an intermediate level between lower level health centers and higher referral health facilities [19]. This might be due to when the health facility location is convenient for patients and access to transportation, patients easily travel to and visit the health facility to utilize health care.

Despite the study identified the factors that contribute to outpatient self-referral to referral health facilities bypassing of proximal health facilities, the sample of the study was derived from a single referral health facility and the findings may differ in other areas of Ethiopia. The data was collected over a short time period and therefore could be subject to seasonal variations in reasons why outpatients self-refer to referral health facilities bypassing the proximal health facilities. The exclusion of seriously ill patients from the study may introduce bias as these patients may have been more likely to self-refer. In this case, the figures for outpatient self-referral would be an underestimate.

\section{Conclusion}

The proportion of outpatient self-referral to referral hospitals bypassing the proximal health facilities was high. Referral information on referral linkage of health facilities, perception of patients about their severity of illnesses and confidence of patients in getting the type of health care providers they want to see at the facilities were the individual factors that influence outpatient self-referral to referral hospitals whereas unavailability of laboratory services, adequate drugs that patients expect to get from the health facilities, quality of health services, convenient location and accessibility of the health facilities to transportation were major institutional factors that influence the outpatients selfreferral to referral health facilities.

So, the Federal Ministry of Health and Regional Health Bureau should develop monitoring systems of referral linkage of health facilities to strengthen referral systems at all levels of health facilities and ensure health services needed to be delivered at lower level health facilities. The health care providers should create awareness in the community to visit the proximal health facilities early when they sick for any health problems and about referral linkages of health facilities. Further study research may be useful in the future to evaluate the cost of outpatient self-referral with the perspectives of patients and the health care system.

\section{Acknowledgements}

We are grateful to Jimma University, the study participants and our special thanks go to administrative and medical staffs at Nekemte referral hospital for their support of this study.

\section{References}

[1] Henery J. Focus on health care disparities key facts. Kaiser Family Foundation. 2012; 2-3.

[2] Syed M, Bushra B, Iqbal A, etal. Bangladesh Health system Review. Health systems in Transitions. WHO, 2015; 5 (3): 142-152. 
[3] Macintyre K, Megan L, David R, etal. Barriers to Referral in Swaziland: Perceptions from providers and Clients of System under Stress. World and medical and health policy. PSO 2011. Manuscript 1183; 24-26.

[4] Health Sector Transformation plan /HSTP2015/2016-2020/. Ethiopian federal ministry of health. Addis Ababa, Ethiopia. 2015; 41-43.

[5] Studying the healthcare network and Analyzing Disrupting Health sector. World health organization. WHO/HAC/MAN/.2008; 8 rev 1: 281-289.

[6] Mojaki ME, Basu D, Letskokgohka ME, Govender M. Referral steps in district health system are side-stepped. Scientific letters. SAMJ. 2011; 101 (2): 109.

[7] Abrahim O, Linnander E, Mohammed H, Fetene N, Bradley E. A Patient-Centered Understanding of the Referral System in Ethiopian Primary Health Care Unit. PloSONE. 2015; 10 (10): 1-10. DOI: 10.1371/journal.pone.0139024.

[8] Wolkite O, Waju B, GebeyehuT. Magnitude and Determinants of Self-Referral of Patients at a General Hospital, Western Ethiopia. Science Journal of Clinical Medicine. 2015; 4 (5): 86-92. Doi: 10.11648/j.sjcm.20150405.12.

[9] Stewart G. The Increasing Importance of Physician to Physician Referrals. Health care success. 2014.

[10] Karimollah H. Sample size determination in epidemiological studies. Caspian J Intern Med. 2011; 2 (4): 289-298.

[11] Armonk. IBM Corp. IBM SPSS Statistics for Windows, Version 20.0. NY: IBM Corp, Released 2011.
[12] Nath B, Kumari R, Tanu N. Utilization of the health care delivery system in a district of north India. East African Journal of Public Health. 2008; 5 (3): 147-153.

[13] Daudi O, Naboth A, Lawrence M, Leonard L. Referral pattern of patients received at the national referral hospital: Challenges in low income countries. East Africa Journal of Public Health. 2008; 5 (1): 7-8.

[14] Yaffee A, Whiteside L, Oteng R, etal. By passing proximal health care facilities for acute care: a survey of patients in a Ghanaian Accident and Emergency Centre. Tropical medicine and International Health. 2012; 17 (6): 777-781. Doi: 10.1111/j.1365-3156.2012.02984.

[15] Emma S, Jonathon K. Direct access and patient self-referral. WCPT Keynotes/ Direct access. World Confederation for Physical Therapy. 2011; 1-2.

[16] Teresita A. The determinants of health care seeking and bypassing of health care facilities in Kenya. 2014; 19-24.

[17] Christopher B, Jonathan P, Jinnet F, etal. Self-referral in Pointof-Service Health Plans. JAMA. 2010; 285 (17): 2223-2234.

[18] Mahindra F. Determinants of self-directed referral amongst patients seeking health services at Kenyatta national hospital. Nairobi. 2013; 39-50.

[19] Kumiko O, Victor M, Naruo U, Gen O. Study of a patient referral system in the Republic of Honduras. Health Policy and Planning. Oxford University Press. 1998; 13 (4): 436-440. 